\title{
Empowering staff in dementia long-term care: towards a more supportive approach to interventions
}

Daniela Figueiredo ${ }^{\mathrm{a}}$, Ana Barbosa ${ }^{\mathrm{b}}$, Joana $_{\mathrm{Cruz}}^{\mathrm{c}}$, Alda Marques ${ }^{\mathrm{d}} \&$ Liliana Sousa $^{\mathrm{e}}$

${ }^{a}$ Higher School of Health, University of Aveiro, Portugal; Unidade de Investigação e Formação sobre Adultos e Idosos, University of Porto, Porto, Portugal

${ }^{b}$ Higher School of Health, University of Aveiro, Portugal

${ }^{c}$ Higher School of Health, University of Aveiro, Portugal

${ }^{d}$ Higher School of Health, University of Aveiro, Portugal

${ }^{e}$ Department of Health Sciences, University of Aveiro, Portugal; Unidade de Investigação e Formação sobre Adultos e Idosos, University of Porto, Porto, Portugal

Corresponding author:

Daniela Figueiredo

University of Aveiro - Higher School of Health,

Campus Universitário de Santiago, 3810-193 Aveiro, PORTUGAL

Tel.: + 351234372 457; Fax: +351 234401597

Email: daniela.figueiredo@ua.pt 
Empowering staff in dementia long-term care

\section{Empowering staff in dementia long-term care: towards a more}

\section{supportive approach to interventions}

Objective: Staff is often considered a privileged vehicle to implement nonpharmacological approaches to the care of residents with dementia, through educational or training interventions. However, staff emotional needs resulting from dementia care demands are frequently neglected. This pilot-study aimed to develop and assess a psycho-educational programme for staff in care homes designed to: increase knowledge and competences regarding dementia care; promote skills to integrate motor and multisensory stimulation in daily care to residents with dementia; develop coping strategies to manage emotional work-related demands.

Methods: During 4 months, 6 staff members of a care home received 8 psychoeducational group sessions held fortnightly and individualized assistance during the provision of morning care to 6 residents with advanced dementia. An audio-recorded focus group interview with staff after the intervention and 12 video-recordings of residents' behaviour during morning care (6 pre-, 6 post-intervention) were performed to assess the programme.

Results: Staff reported a number of benefits from their participation: acquisition of new knowledge and competences; demystification of pre-existing beliefs related to people with advanced dementia; group cohesion; self-worth feelings; and positive coping strategies. Also, a trend towards improvements at residents' levels of communication and involvement in morning care routines was found.

Conclusion: The findings suggest the need of interventions to extend those objectives exclusively centred on education of staff and focused on promoting residents' wellbeing, by also allowing workers to feel supported and empowered.

Keywords: dementia, care staff, psycho-educational support, motor stimulation, multisensory stimulation 
Empowering staff in dementia long-term care

\section{Empowering staff in dementia long-term care: towards a more}

\section{supportive approach to interventions}

\section{Introduction}

Dementia is a common reason for institutionalization (Testad, Mikkelsen, Ballard \& Aarsland, 2010). Its growing prevalence (Ferri et al., 2005) poses several challenges to long-term care facilities. Approximately two-thirds of the institutionalized residents have dementia, and $90 \%$ of them present behavioural symptoms (American Psychiatric Association [APA], 2007), which are considered to be one of the most difficult issues faced by staff and administrators of today's long-term care institutions (Cassidy \& Sheikh, 2002; Kuske et al., 2009). Another important issue for care home administrators is how to maintain acceptable standards of care and quality of life in dementia with limited funds and human resources, and care staff with inadequate training (Chenoweth et al., 2009). This concern is relevant in Portugal, as at international levels, since there are few specialized care units for people with dementia. Thus, most of the long-term placements occur in traditional care homes, also known as “old people's homes", where assistance to older and frail people is provided at a non-nursing-home level of care, by care staff with insufficient specialized training (Beer et al., 2010; Kuske et al., 2007; Moniz-Cook et al., 1998). The assistance provided in these facilities tends to neglect the psychosocial needs of persons with dementia, and the use of physical and/or pharmacological restraints are a common practice (Burgio et al., 2002; Camp, CohenMansfield \& Capezuti, 2002; Moniz-Cook, Stokes \& Agar, 2003).

Over recent years, motor stimulation (MS) and multisensory stimulation (MSS) have become increasingly used non-pharmacological approaches to dementia care, particularly at advanced stages of the disease (Sidani, LeClerc \& Streiner, 2009; Weert 
Empowering staff in dementia long-term care

et al., 2005a) . Motor stimulation is characterized by specific exercises known to improve mobility (Tappen, Roach, Applegate \& Stowell, 2000) and has been shown to delay Activities of Daily Living decline in residents with dementia (Rolland et al., 2007). Multisensory stimulation is an intervention that actively stimulates the senses with no need for higher cognitive processes, such as memory or learning (Baillon et al., 2005; Weert, Dulmen \& Bensing, 2008). It requires a resident-oriented attitude, knowledge and skills, allowing caregivers to incorporate, in care provision, personal circumstances such as lifestyle, preferences, desires and cultural diversity, in order to achieve or maintain a state of well-being. Therefore, MSS matches the concept of "person-centeredness" (Weert et al., 2004), which is increasingly being regarded as synonymous of best quality of care (Edvardsson, Fetherstonhaugh, Nay \& Gibson, 2010). When introduced in daily care routines, MSS has been shown to impact positively on residents' behaviours and mood (Weert et al., 2005b; Weert et al., 2006), reduce anxiety (Finnema et al., 2005) and increase resident-staff interactions (Weert et al., 2005a).

Staff has been considered a privileged vehicle to implement these approaches to the care of people with dementia as they maintain the most direct contact with them (Sloane et al., 2007; Weert et al., 2005a). However, staff intense involvement with residents can make them especially vulnerable to stress and burnout (Lann-Wolcott, Medvene \& Williams, 2011), and contribute to health problems, job absenteeism, and high-turnover (Brodaty, Draper \& Low, 2003; Cohen-Mansfield, 1997; Duffy, Oyebode \& Allen, 2009; McKenzie \& Peragine, 2003). Despite the increasing recognition of staff central role to residents' quality of life, they are poorly supported and valued for their physically and emotionally labor-intensive care (Beck, Ortigara, Mercer \& Shue, 1999; Moniz-Cook, Millington \& Silver, 1997; Zimmerman et al., 2005). In the last decade, 
Empowering staff in dementia long-term care

several training interventions have been conducted. They are generally centred on the education of staff, aiming to modify their knowledge and skills regarding dementia care (Beer et al., 2010; Cohen-Mansfield, 2004; Kuske et al., 2007; Livingstone et al., 2005). Yet, the provision of emotional support is scarce despite staff well-reported stress and burnout (Brodaty, Draper \& Low, 2003; Cassidy \& Sheikh, 2002; Duffy, Oyebode \& Allen, 2009) and its recognized association with the quality of care provided (Redfern, Hannan, Norman \& Martin, 2002) and residents' well-being (Cheung \& Chow, 2006). While it has been suggested that effective interventions should entail a multicomponent approach (Brodaty Draper \& Low, 2003), to our knowledge, none intervention until now combined education for staff to integrate motor and multisensory stimulation in the daily care of residents with dementia, and support to manage workrelated emotional demands. Thus, this pilot-study aimed to develop and evaluate a psycho-educational programme for staff in care homes designed to: increase staff knowledge and competences regarding dementia care; afford staff with skills to integrate MSS and MS in daily care to residents with dementia; provide staff with coping strategies to manage emotional work-related demands.

\section{Methods}

\section{Design and Setting}

A pilot-study was conducted in a traditional long-term care home for older people in the central region of Portugal (district of Aveiro), between November 2009 and February 2010. A semi-structured interview with the care home administrator had determined if the facility met the following inclusion criteria: willingness and agreement to participate in the programme; no substantial organizational changes during the study period; no simultaneous participation in similar studies. The facility had 53 licensed beds, 21 of 
Empowering staff in dementia long-term care

which were occupied by residents with dementia. Qualitative data on staff and quantitative data on residents were collected to help understand the experiences and potential benefits of the programme.

\section{Participants}

After administrator's approval, the service manager was asked to identify eligible staff participants who maintained direct contact with residents with dementia during daily care provision. Staff members who were only working at night were excluded. Ten staff members were identified. Potential participants were individually informed about the study purposes and invited to participate. Nine members agreed to participate. Written informed consent was obtained. Prior to the start of the programme, 3 members had to abandon the study ( 1 due to health problems, 1 for personal reasons, 1 because the person quitted her job). Thus, 6 formal caregivers have participated. Participants were all female. The average age was 40 years $(\mathrm{SD}=11.91)$, ranging from 23 to 51 years old. Half of the sample was working at the care home for more than 3 years (Table 1).

Six residents with dementia diagnosis were recruited in order to analyse the impacts of the programme on their behaviour. They had to present clinical diagnosis of moderate to severe dementia according to DSM-IV criteria (APA, 2002), had a score of $\geq 11$ in the Cognitive Impairment Test of the Portuguese version of EASYCare (Sousa, Figueiredo \& Galante, 2003), need assistance with personal care and no additional psychiatric diagnosis. Written informed consent was obtained from the residents' relative legal guardian: 4 children, 1 spouse and 1 brother. Residents were mostly female $(n=4)$. The mean age was 80.83 ( $S D=10.87)$, with a range of 66 to 93 years old, and presented distinct levels off functional ability in Barthel Index's (Mahoney \& 
Empowering staff in dementia long-term care

Barthel, 1965): 3 with high levels of dependency, whereas the other 3 revealed moderate to slight dependency.

(Insert Table 1)

\section{Programme's design}

There are few systematic data available regarding educational and supportive needs of care staff. Thus, a focus-group interview with staff was conducted at the facility prior to the intervention aiming to get a deep understanding about their perceived needs, competences and expectations towards the programme. Data allowed the design of the intervention and the identification of important topics. Overall, staff reported the need for (Barbosa et al., 2011): information about dementia; practical and simple tools and strategies to improve care; communication skills; coping skills to prevent and manage stress. Also, they expected to improve care delivery, gain confidence on their competences and improve their self-efficacy.

The programme combined 8 psycho-educational group sessions of 90 minutes with staff held fortnightly, and individualized assistance during personal care to sustain the implementation of new knowledge. The whole programme was conducted at the care facility throughout a period of 4 months.

\section{Psycho-educational sessions}

Each session comprised an educational and a supportive component (table 2).

The educational component aimed to provide staff with specialized knowledge regarding dementia condition and dementia care. Special attention was given to: myths and misconceptions related to dementia syndrome, especially at advanced stages of the disease; asymmetry of the staff-resident relation and the importance of understanding 
Empowering staff in dementia long-term care

the effects of dementia on social and self-care abilities of residents; the relevance of maintaining the remain abilities and MS and MSS strategies to integrate during the provision of personal care; effective strategies to cope with challenging behaviours. Particular emphasis was also placed on verbal and non verbal communication and other facilitative interaction aspects, such as: recognition of residents' life history, creation of an atmosphere of trust and relaxation and exploration of residents' sensory stimuli preferences.

The supportive component aimed to help staff manage the emotional demands of working in dementia care. Staff members could discuss their experiences about providing care to residents with dementia and their subsequent emotional reactions. A special focus was given to the importance of self-care and wellness promotion (e.g., encouraging staff engagement in regular enjoyable activities or enhancing social networks). Practical strategies to cope with work-related stress were given, namely, assertiveness or problem-solving. Also relaxation techniques were practiced at the end of each supportive component (e.g., abdominal breathing, progressive muscle relaxation, stretching, and guided imagery) aiming to aware staff of its benefits and to give them an opportunity to relax for some minutes.

Various didactic methods, such as case examples based on staff past experiences, group discussions, home-work exercises, role-playing and brainstorming, were used during the psycho-educational sessions. All participants were given handouts which summarized the most relevant information. The provision of written information reinforces learning and serves as a resource to support staff in their day-to-day practice.

All psycho-educational group sessions were conducted by a multidisciplinary team: a psychologist with training in psycho-educational groups, and a gerontologist and a physiotherapist with experience in dementia care, particularly in providing motor 
Empowering staff in dementia long-term care

and multisensory stimulation. These professionals assumed the role of facilitators by: supporting staff in their doubts and to share their experiences; validating and normalizing certain feelings such as exhaustion, frustration or powerlessness; and assuming an active and empathic attitude.

(Insert Table 2)

An example: describing the first psycho-educational group session

The first session began with presenting the intervening people (group facilitators and participants), the overall program and the structure of the current session. The educative component started with a brief discussion regarding basic information about dementia. Participants had the opportunity to ask questions and clarify doubts. Practical questions like how to react and deal with challenging behaviours prevailed. Strategies to stimulate the senses during care routines, through MSS, were also approached. Participants were clarified about: the importance of the senses as a way to communicate effectively with residents in advanced stages of dementia; the need of adjusting the stimuli to residents' needs and preferences; and the importance of assessing resident's life history. Olfaction was the first of the five senses to be discussed. Through a discussion group, staff explored a number of practical strategies to stimulate residents' olfaction during the day (e.g., use of essential oils during bath; use of food extracts, such as mint or cinnamon, during meals; put resident's favourite perfume).

The supportive component aimed to help staff members to reflect and identify the positive and negative impacts of their caregiving experience on their personal, professional and familiar life. The most reported positive impacts were: personal realization, preparation for possible personal or familiar situations in the future, satisfaction for providing the best possible care and consciousness that the residents 
Empowering staff in dementia long-term care

have their needs addressed. The most identified negative impact was the fear of being, one day, in the same situation. As a relaxation method, the abdominal breathing was performed (Payne, 2000). At the end, participants were given a home assignment of register their sources of stress and respective used management strategies, as a way to perceive what situations made them feel stressed. All the following psycho-educational sessions began with group discussions of their degree of success with the task they have been given in each previous session and the doubts and concerns regarding their week of practicing.

\section{Individual assistance and feedback}

Between group sessions, each staff member was individually assisted in the workplace by the gerontologist and the physiotherapist. This assistance occurred in the following three days after each psycho-educational session, during morning care provision when most staff-residents interactions occur (Sloane et al., 2007). Morning care, which comprises activities related to bathing, dressing and toileting, is a suitable moment to stimulate the senses (olfactory, tactual, auditory, visual) and to integrate multisensory (e.g., nice smelling soap, soft towels, nature sounds) (Weert et al., 2005a) and motor stimulation (e.g., encourage the person to perform one task or part of it, like wash the face or reach the towel, by giving him/her small and simple instructions, step by step). Individual assistance is crucial as didactic sessions alone are unlikely to promote practice change (McCabe et al., 2007) and interventions with ongoing support demonstrated sustained implementation of new knowledge (Kuske et al., 2007; Vernooij-Dassen \& Olde Rikkert, 2004; Weert et al., 2004). Thus, these professionals 
Empowering staff in dementia long-term care

helped staff to implement the new knowledge, clarified doubts that could have been emerged from sessions and made suggestions to better implement MS and MSS.

\section{Assessment}

Data were collected in order to identify programme's impacts on staff and residents. Creating opportunities to address staff participants' opinions about interventions (e.g., their perspective about the contents, the feasibility of some dementia care strategies in daily practice, barriers to practice change) is determinant for further development of innovative approaches to programmes and to understand its effectiveness in achieving intended goals. Also, understanding the impacts of the programme on residents is crucial as even if staff knowledge and skills have changed, this may not lead to a change in residents' behaviour.

Thus, a focus-group interview was held with 5 staff participants two weeks after the programme. One participant missed the interview due to personal medical reasons. Focus-group interviews are often used to collect qualitative data in order to study and describe the context and components of events or experiences. As a data collection method, it promotes participatory research since participants feel valued as their feelings, perceptions and views are explored and considered by researchers (Kitzinger, 1995). The purpose was to obtain in-depth views regarding staff participants' experiences within the intervention. Topics were carefully structured and included staff's perceptions about the adequacy and structure of the programme and its impacts on staff's knowledge, competences, care practices and well-being. The interview lasted approximately 2 hours, was audio-recorded and transcribed.

Video-recordings were used to analyse programme's impacts on residents' behaviour during morning care. Data were collected immediately before and two weeks 
Empowering staff in dementia long-term care

after the programme. Video-recordings were performed during upper-body washing, teeth-brushing, dressing and shaving. Several video-recordings were performed prior to data collection to decrease the effect of the camera on staff and residents' behaviour. Twelve video-recordings were obtained ( 6 before and 6 after the programme). The average duration of video-recordings was 3.92 minutes.

\section{Data Analysis}

Focus-group interview transcript was analyzed using qualitative content analysis. The text was read repeatedly by two of the authors that acted as independent judges. The first readings aimed to construct a sense of the text as a whole, the second readings were to indentify meaning units according to the aim of the study, and the third readings were set to condense the meaning units and cluster these into major categories. Thereafter, a formal meeting with the two judges was held to compare individual analysis and to agree on final categories. A final categorisation was then drafted. Critical feedback was performed by the other authors.

Video assessment of residents' behaviour was conducted by two independent observers, who were blinded to the phase of the intervention (before/after the programme), using the Observer XT software (Noldus International Technology, Wageningen, Netherlands). This software allowed the analysis of the duration of a list of behaviours (ethogram), previously designed by the authors according to the existing literature (Weert et al., 2005a; Wood, Womack \& Hooper, 2009) and preliminary observations of the video-recordings. Caregiver-direct gaze (the resident looks at the caregiver), verbal communication (the resident articulates words or sentences with meaning to voluntarily communicate with the caregiver), closed eyes (the resident close his/her eyes and keep them closed for more than one second) and task engagement (the 
Empowering staff in dementia long-term care

resident moves the body or a body part in order to, voluntarily or solicitously, perform a task or part of it) categories composed the ethogram (Cruz et al., 2011). The interobserver reliability analysis was conducted for the duration of each behaviour category, in both phases. Intraclass Correlation Coefficient (ICC) (Fleiss, 1986; Shrout \& Fleiss, 1979) equation (2.1) was used to assess the relative reliability. The absolute reliability was analysed through the Bland and Altman plots (Bland \& Altman, 1986). Results have been published elsewhere (Cruz et al., 2001). The categories were analysed through descriptive and inferential statistics analysis using PASW Statistics version 18.0 for Windows (SPSS Inc., Chicago, Illinois). The differences between pre- and post-intervention were examined using the nonparametric Wilcoxon matched pairs signed-rank test a $p$ value below .05 was considered statistically significant.

\section{Results}

\section{Staff perspectives regarding the structure and organization of the programme}

Participants considered that the number, duration and periodicity of the psychoeducational group sessions were appropriate. They also emphasised the importance of facilitators' role and recognised their professional competences. Having professionals that didn't just teach, but also listened was felt as a positive aspect. Participants felt comfortable in the presence of the three professionals and considered that they had complemented each other:

"You came well prepared, knew what it was, were one step ahead ... and the psychologist was very sensitive, a good observer and a reasonable person (...) I noticed many times that he was very supportive." [G., 51 years old]

Overall, participants found the entire contents informative, applicable and very useful. All participants reported explicitly that nothing was useless. In their opinion, the 
Empowering staff in dementia long-term care

information was clear and well structured and the programme suited their expertise and working situation:

"I think that how you prepared... even the small exercises that you brought or the questions ... It made us think ... we stopped and thought." [G., 51 years old]

"All those topics, we have to deal with them here." [M., 45 years old]

"Very appropriate and made us think twice about what we were doing in practice. "[C., 27 years old]

Participants found the materials and didactic methods, such as discussions, group exercises, role-playing or brainstorming, very useful. The availability of written materials (handouts) for each psycho-educational session was highlighted as a very positive aspect because it was written in an understandable manner, without confusing words and very simple.

Individualised assistance was pointed out as a relevant factor for the sustenance of the new knowledge and to facilitate the development of practical skills:

"The individualised assistance reminded us what was learnt in previous sessions, we could talk and share any problem we had... it was great! (...) It was always very helpful to have additional opportunities to ask and clarify our doubts. ” [C., 27 years old]

Time restraint was identified as the unique concern for staff participation in the programme. The sessions deprived them from the short break-time they had to rest. old]

"In order to attend the sessions, I had to spent the time I had for other things" [M., 45 years

\section{Staff perceived benefits from the programme}

The analysis of the focus group interview revealed five major themes related to staff perceived benefits from their participation in the programme: i) acquisition of new knowledge and competences; ii) demystification of pre-existing beliefs related to people with advanced dementia; iii) group cohesion; iv) self-worth feelings; and v) positive coping strategies. 
Empowering staff in dementia long-term care

Acquisition of new knowledge and competences

The acquisition of new knowledge was identified by participants as one of the main benefits from their participation. Particular relevance was attributed to the sessions which addressed MSS because they deal all the time with their senses:

"I think we have to be always very aware to the senses of our residents. (...) If one is more fragile than others, we must be more aware and think ...This topic was very well developed. Senses are very important in these issues that you brought here!" [G., 51 years]

The contents of the sessions were helpful in enabling staff members to reflect on their own practice. For example, one participant referred that some of the skills they had previously used, but were not aware of their importance when caring for patients with dementia:

"Sometimes it was like a 'click'...for some points that you warned we thought 'we really seem to do these things and not reflect in what we are doing'. And you allowed us to reflect." [G., 51 years old]

The initial resistance to the provision of new care practices, like the application of MS and MSS during the provision of personal care, was dissipated, with one participant reporting that:

"I really at first, making an assessment, I thought it was all very theoretical. It was good, but maybe not to put into practice and (...) I really saw that it could be used in practice." [P., 45 years old]

Others strengthen the motivation to apply knowledge and improve practice:

"Knowledge, new knowledge. I have learned a lot with this programme. We learned (...) and put [the acquired knowledge] into practice, which was essential. " [C., 27 years old]

"We recalled some aspects, and at the same time we recall them, we put in practice. " [M., 45 years old] 
Empowering staff in dementia long-term care

\section{Demystification of pre-existing beliefs}

Pre-existing myths often associated with dementia were challenged. The attitudes towards the residents had changed, because participants previously thought that almost nothing could be done with people at advanced stages of dementia. The programme provided staff members with a better idea of what works well with residents, showing that there are strategies, like MSS and MS, they can integrate in the provision of personal care to communicate appropriately with them:

"Some [strategies] I had already put it into practice but others...I experienced many. It was impressive! We thought they were not able to do nothing, for example Mr. F., and he really does a lot." [C., 27 years old $]$

\section{Group cohesion}

Overall, staff members valued the supportive component. Participants reported that they often feel unsupported and had identified the need of a period during their work time where they could discuss their problems and share experiences. Thus, the programme was felt as an opportunity to increase the group cohesion and to share experiences about their difficulties and work-related stress. It also promoted a greater proximity between members, by allowing the dialogue and confrontation of different perspectives:

\footnotetext{
"When we joined, one spoke about a thing, another of another thing (...) and we reflected together." [M., 45 years old]

"Sometimes we meet in the lobby and it is just a 'hello!', but here we had the opportunity to know a little bit more of each other." [P., 45 years old]
}

\section{Self-worth feelings}

The programme also contributed to validate some competences. Several participants reported feeling valued, as they identified that the abilities they had acquired during their caregiving experience and efforts were recognised as adequate and validated by the facilitators: 
Empowering staff in dementia long-term care

"I think it also helped us to understand whether the things we did and the decisions we took were right or not... now we realize that we acted exactly the way we should. It makes us more certain of our decisions. ” [P., 45 years old]

\section{Positive coping strategies}

Participants placed emphasis on the importance of relaxation techniques. The provided relaxation time allowed moments of rest and enabled staff to understand that self-care strategies could impact positively on their well-being. Also, participants realized that their well-being may be closely related to residents' well-being:

"We could relax in situations of higher strain." [M., 45 years old]

"I think that the moments of relaxation helped us to understand that if we feel happy, we can contribute to the well-being of the elderly. " [G., 51 years old]

Problem-solving skills were also identified as a major benefit of the programme:

"That part of working with the colleagues, of us to react to a problem...how to solve problems... was very important. Because I had a problem, but in many occasions it was never solved, and I thought that it would not be solved anyway. But I tried and resulted! [G., 51 years old]

\section{Impacts of the programme on residents' behaviour}

The impacts of the programme on residents' behaviour (Figure 1) suggest an increase of the duration of caregiver-direct gaze (from 0.67 to 4.17 seconds) and a decrease in closed eyes (from 32.58 to 19.42 seconds). Concerning residents' engagement, there was an increase in both solicited and voluntary engagement categories after the intervention. No statistical significant differences were found.

(Insert Figure 1) 
Empowering staff in dementia long-term care

\section{Discussion}

The purpose of this pilot-study was to explore the effectiveness of a psycho-educational programme designed to address some of the main challenges faced by care staff of residents with dementia in traditional care homes: lack of specialized knowledge about dementia; need of effective skills to increase the quality of care; and need of support to coping with emotional work-related demands.

The results suggest a trend towards improvements in residents' levels of communication and involvement in morning care routines after the programme.

Although the differences were not statistically significant, the residents with dementia tend to present higher levels of caregiver direct-gaze and task engagement with a reduction of the duration of closed eyes, in comparison with their baseline responses, showing less inactive behaviours during their personal care. These promising results may be explained by the multisensory and motor stimulation strategies introduced by staff in the daily care provision during the programme. Therefore, it is suggested that affording staff with skills to provide residents with appropriate levels of stimulation, it is likely that even people in advanced stages of dementia will show awareness and express themselves through their behaviour and engagement during care (Wells \& Dawson, 2000), thus potentially improving their well-being and quality of life (Lawton, 1994). There are few research studies which have trained care staff with basic skills to implement multisensory (Weert et al., 2005a) or motor (Sidani, LeClerc \& Streiner, 2009) stimulation in daily care provision to residents with dementia. Therefore, this study supports the implementation of these strategies by care staff, by suggesting an improvement of interaction behaviours and engagement of the residents with moderate to severe dementia. 
Empowering staff in dementia long-term care

However, education in the use of motor and multisensory stimulation may not be enough to explain the current tendency of the results, which can also be attributable to the supportive component of the intervention. Extensive literature exists on training direct care providers to reduce inappropriate behaviours of persons with dementia, improve communication with them and understand their needs (Cohen-Mansfield, 2004; Kuske et al., 2007). But unlike previous studies, which primarily focus on the wellbeing of the residents with dementia, this research had a broader focus: it also attended staff's emotional support needs. Several benefits were reported from staff participation in the programme. They considered that the programme: afforded them with new insights and skills; help them to feel valued and recognised in their efforts and competences; provided them with new problem-solving skills related to work demands; and increased awareness to the importance of their own well-being. Therefore, interventions that lead to perceptions of increased competence and to feelings of being attended in emotional needs might enhance staff motivation and engagement in providing adequate care. Besides, as underlined by MacKenzie \& Peragine (2003), staff recognition about their role on residents' improvements is particularly relevant, as the development of a sense of self-efficacy and competence has the potential to reduce or prevent the impacts of stress and burnout.

The overall results suggest that the combination of education and support (psycho-educational sessions) and individualized orientation (after sessions) can be appropriated to introduce new approaches to dementia care and improve the quality of care and the well-being of both staff and residents. Moreover, the study highlight the need of interventions that extend those objectives exclusively targeted to residents' well-being and centred mainly on education, by also allowing workers to feel supported and empowered. Previous research (Edberg et al., 2008) have underlined that care 
Empowering staff in dementia long-term care

providers' experience of strain in dementia care is associated with a desire to give the best care by trying to alleviate people's suffering and enhance their quality of life. That is, when caregivers don't have the resources, opportunity or ability to do this, they can experience strain. Therefore, recognize staff expertise, afford them with practical skills and resources to enhance residents' well-being, allow them to share and discuss significant issues concerning dementia care, acknowledge their concerns and emotional needs, and support them to develop effective coping strategies might be successful in promoting a sense of mastery and self-efficacy and, consequently, improve the quality of care provided.

Further, the current promising results may also be explained by the inclusion of staff perceived needs and desired goals in the design of the programme. This not only promoted participation but also allowed the development of a sense of ownership among staff. Engaging staff in the design of future interventions (Nolan et al., 2008) and tailoring them to the specific social and cultural settings in which they are to be implemented (Brooker, Woolley \& Lee, 2007) seems to be essential to establish the appropriateness of the intended programme.

However, even though that attending to educational and supportive needs of staff could lead to a change in practice, programme per se might not be enough to provide the "miracle answer" to the challenges faced in traditional care homes. Some staff members found it difficult to attend psycho-educational sessions. Some attended the sessions in their own time. Previous studies have reached similar results (Kuske et al., 2007; Visser et al., 2008). Extending the focus of interventions to all levels of staff (both qualified and non qualified, senior personal and managers) might be necessary in order to raise awareness across the entire organization to engage and embrace change towards new approaches regarding dementia care. 
Empowering staff in dementia long-term care

Although encouraging, the findings from this study are limited by the inclusion of a single residential care home. The non-statistically significant improvement found in the residents' engagement during the morning care tasks may be related with the small sample size. However, the methodology used to assess residents' behaviours, based on the observation of video-recordings collected within a naturalistic approach overcome some methodological limitations in previous studies, as data has been mostly assessed by checklists completed by staff members (Kuske et al., 2007). This introduces a bias, as staff participants may be motivated to report improvements in residents' behaviours (McCabe, Davison \& George, 2007). In any case, the authors recommend the implementation of similar interventions in larger samples, with a randomized controlled design, and combining qualitative and quantitative outcome measures, at both staff and residents' levels, to investigate the extent of these benefits.

In conclusion, findings from this pilot-study suggest that programmes that attend to both educational and supportive needs of staff are a promising approach to improve dementia care in care homes, that might increase the well-being of all the involved: staff and residents. As suggested by previous research, workers who feel valued and perceived themselves to provide good and adequate care are more likely to report more satisfaction (Zimmerman et al., 2005) and to experience a profound sense of purpose in their work (Secrest, Iorio \& Martz, 2005). In the limit, this could lead to a virtuous cycle, where the development of a sense of self-efficacy and competence could lead to the well-being of the cared person that, in turn, would reinforce a sense of well-being and accomplishment in their caregivers. 
Empowering staff in dementia long-term care

\section{Acknowledgements}

This work was supported by Fundação Calouste Gulbenkian. The authors would like to thank to the participation of managers, staff members and residents with dementia of the care home where the study was conducted. They also would like to thank to Dr. Álvaro Mendes for his important support in the conduction of the psychoeducational group sessions and Professor Liliana de Sousa and Dr. Ana Magalhães for their valuable comments and important support during the study design and data analysis. 
Empowering staff in dementia long-term care

\section{References}

American Psychiatric Association. (2002). DSM-IV-TR - Manual de Diagnóstico e Estatística das Perturbações Mentais (4ª ed). Lisboa: Climepsi Editores.

American Psychiatric Association. (2007). Practice guideline for the treatment of patients with Alzheimer's disease and other dementias. ( $2^{\text {nd }}$ ed.). Washington, DC: Author. doi: 10.1176/appi.books.9780890423967.152139

Baillon, S., Diepen, E. van, Prettyman, R., Redman, J., Rooke, N. \& Campbell, R. (2004). A comparison of the effects of Snoezelen and reminiscence therapy of the agitated behavior of patients with dementia. International Journal of Geriatric Psychiatry, 19, 1047-1052. doi: 10.1002/gps.1208.

Barbosa, A.L., Cruz, J., Figueiredo, D., Marques, A. \& Sousa, L. (2011). Cuidar de idosos com demência em instituições: competências, dificuldades e necessidades percepcionadas pelos cuidadores formais. Psicologia, Saúde \& Doença, 12(1) (in Press).

Beck, C., Ortigara, A., Mercer, S. \& Shue, V. (1999). Enabling and empowering certified nursing assistants for quality dementia care. International Journal of Geriatric Psychiatry, 14, 197-212. doi: 10.1002/(SICI)1099-

1166(199903)14:3<197::AID-GPS972>3.0.CO;2-Q

Beer, C., D., Horner, B., Almeida, O. P., Scherer, S., Lautenschlager, N. T., Bretland, N., ... Flicker, L. (2010). Dementia in residential care: education intervention trail (DIRECT); protocol for a randomized controlled trial. Trials, 11, 1-6. Retrieved from http://www.trialsjournal.com/content/11/1/63 
Empowering staff in dementia long-term care

Bland, M.J. \& Altman D.G. (1986). Statistical Methods for Assessing Agreement between Two Methods of Clinical Measurement. Lancet. 327(8476), 307-310. doi: $\underline{10.1016 / \mathrm{S} 0140-6736(86) 90837-8}$

Brodaty, H., Draper, B., \& Low, L.F. (2003). Nursing home staff attitudes towards residents with dementia: strain and satisfaction with work. Journal of Advanced Nursing, 44(6), 583-590. doi: 10.1046/j.0309-2402.2003.02848.x.

Brooker, D. J., Woolley, R. J. \& Lee, D. (2007). Enriching opportunities for people living with dementia in nursing homes: An evaluation of a multi-level activitybased model of care. Aging \& Mental Health, 11(4), 361-370. doi: 10.1080/13607860600963679.

Burgio, L. D., Stevens, A., Burgio, K., L., Roth, D. L., Paul, P. \& Gerstle, J. (2002). Teaching and maintaining behavior management skills in the nursing home. The Gerontologist, 42(4), 487-496. doi: 10.1093/geront/42.4.487

Camp, C., J., Cohen-Mansfield, J. \& Capezuti, E. (2002). Use of nonpharmachologic internventions among nursing home residents with dementia. Psychiatric Services, 53(11), 1397-1401.

Cassidy, E. L., \& Sheikh, J. I. (2002). Pre-intervention assessment for disruptive behavior problems: a focus on staff needs. Aging \& Mental Health, 6(2), 166-171. doi: 10.1080/1360786022012672 7

Chenoweth, L., King, M., T., Jeon, Y., Brodaty, H., Stein-Parbury, J., Norman, R., ... Luscombe, G. (2009). Caring for aged dementia care resident study (CADRES) of person-centred care, dementia-care mapping, and usual care in dementia: a cluster-randomised trial. The Lancet Neurology 2009, 8:317-325. doi: $10.1016 / \mathrm{S} 1474-4422(09) 70045-6$ 
Empowering staff in dementia long-term care

Cheung, C. K. \& Chow, E. O (2006). Spilling over strain between elders and their caregivers in Hong Kong. International Journal of Aging and Human Development, 63(1): 73-93.

Cohen-Mansfield, J. (1997). Turnover among nursing home staff. A review. Nursing Management, 28(5), 59-64.

Cohen-Mansfield, J. (2004). Nonpharmachologic interventions for inappropriate behaviors in dementia: A review, summary, and critique. FOCUS:The Journal of Lifelong Learning in Psychiatry, 2(2), 288-308.

Cruz, J. P., Marques, A., Barbosa, A. L., Figueiredo, D. \& Sousa, L. X. (2011). Effects of a motor and multisensory-based approach on residents with moderate-to-severe dementia. American Journal of Alzheimer's Disease \& Other Dementias (In press).

Duffy, B., Oyebode, J. R. \& Allen, J. (2009). Burnout among care staff for older adults with dementia. The role of reciprocity, self-efficacy and organizational factores. Dementia, 8(4), 515-541. doi: 10.1177/1471301209350285

Edberg, A. K., Bird, M., Richards, D. A., Woods, R., Keeley, P. \& Davis-Quarrell, V. (2008). Strain in nursing care of people with dementia: Nurses' experience in Australia, Sweden and United Kingdom. Aging \& Mental Health, 12(2): 236-243. doi: 10.1080/13607860701616374.

Edvardsson, D., Fetherstonhaugh, D., Nay, R. \& Gibson, S. (2010). Development and initial testing of the Person-centered Care Assessment Tool. International Psychogeriatrics, 22(1), 101-108. doi:10.1017/S1041610209990688

Ferri, C. P., Prince, M., Brayne, C., Brodaty, H., Fratiglioni, L., Ganguli, M., ... Scazufca, M. (2005). Global prevalence of dementia: a Delphi consensus study. The Lancet, 366, 2112-2117. doi: 10.1016/S0140-6736(05)67889-0 
Empowering staff in dementia long-term care

Finnema, E., Dröes, R. M., Ettema, T., Ooms, M., Adèr. H., Ribbe, M., Tilburg, W. van (2005). The effect of integrated emotion-oriented care versus usual care on elderly persons with dementia in the nursing home and on nursing assistants: a randomized controlled trial. International Journal of Geriatric Psychiatry, 20, 330-343. doi: 10.1002/gps.1286.

Fleiss, J. L. (1986). Reliability of measurements. In J. Fleiss (ed). The design and analysis of clinical experiments. $1^{\text {st }}$ ed. (pp. 1-14). New York: John Wiley \& Sons.

Kitzinger, J. (1995). Introducing focus groups. British Medical Journal, 311: 299-302.

Kuske, B., Hanns, S., Luck, T., Angermeyer, M. C., Behrens, J. \& Riedel-Heller, S. G. (2007). Nursing home staff training in dementia care: a systematic review of evaluated programs. International Psychogeriatrics, 19(5), 818-841 doi:10.1017/S1041610206004352

Kuske, B., Luck, T., Hanns, S., Matschinger, H., Angermeyer, M. C., Behrens, J. \& Riedel-Heller, S. G. (2009). Training in dementia care: a cluster-randomized controlled trial of a training program for nursing home staff in Germany. International Psychogeriatrics, 21(2), 295-308. doi:10.1017/S1041610208008387

Lann-Wolcott, H., Medvene, L. J. \& Williams, K. (2011). Measuring the personcenteredness of caregivers working with nursing home residents with dementia. Behavior Therapy, 42, 89-99. doi: 10.1016/j.beth.2010.02.005

Lawton, M.P. (1994). Quality of Life in Alzheimer Disease. Alzheimer Disease and Associated Disorders, 8(3), 138-150.

Livingstone, G., Johnston, K., Katona, C., Paton, J. \& Lyketsos, C. G. (2005). Systematic review of psychological approaches to the management of neuropsychiatric symptoms of dementia. American Journal of Psychiatry, 162(11), 1996-2021. doi: 10.1176/appi.ajp.162.11.1996 
Empowering staff in dementia long-term care

MacKenzie, C. S., Peragine, G. (2003). Measuring and enhancing self-efficacy among professional caregivers of individuals with dementia. American Journal of Alzheimer's Disease and Other Dementias, 18(5), 291-299. doi:

$10.1177 / 153331750301800507$

Mahoney, F. \& Barthel, D. (1965). Functional evaluation: the Barthel Index. Maryland State Medical Journal, 14, 56-61. Retrived from http://www.strokecenter.org/trials/scales/barthel_reprint.pdf

McCabe, M.P., Davison, T. E. \& George, K.(2007). Effectiveness of staff training programs for behavioral problems among older people with dementia. Aging \& Mental Health, 11(5), 505 - 519. doi: 10.1080/13607860601086405

McCabe, M.P., Davison, T., Visser, S., Hudgson, C., Buchanan, G. \& George, K. (2007). Effectiveness of staff training programs to manage behavioural problems with dementia. International Journal of Health \& Ageing Management, 1(2), 1123.

Moniz-Cook, E., Agar, S., Silver, M., Woods, R., Wang, M., Elston, C. \& Win, T. (1998). Can staff training reduce behavioural problems in residential care for the elderly mentally ill? International Journal of Geriatric Psychiatry, 13, 149-158. doi: 10.1002/(SICI)1099-1166(199803)13:3<149::AID-GPS746>3.0.CO;2-Q 
Empowering staff in dementia long-term care

Moniz-Cook, E., Millington, D. \& Silver, M. (1997). Residential care for older people: job satisfaction and psychological health in care staff. Health and Social Care in the Community, 5(2), 124-133. doi: 10.1111/j.13652524.1997.tb00107.x

Moniz-Cook, E., Stokes, G. \& Agar, S. (2003). Difficult behavior and dementia in nursing homes: Five cases of psychosocial intervention. Clinical Psychology and Psychotherapy, 10, 197-208. doi: 10.1002/cpp.370.

Nolan, M., Davies, S., Brown, J., Wilkinson, A., Warnes, T., McKee, K., Flannery, J. \& Stasi, K. (2008). The role of education and training in achieving change in care homes: a literature review. Journal of Research in Nursing, 13(5), 411-433. doi: $10.1177 / 1744987108095162$.

Payne, R. A. (2000). Relaxation Techniques (2 ed.). London: Churchill Livingston. Redfern, S., Hannan, S., Norman, I. \& Martin, F. (2002). Work satisfaction, stress, quality of care and morale of older people in a nursing home. Health and Social Care in the Community, 10(6): 512-517. doi: 10.1046/j.1365-2524.2002.00396.x

Rolland, Y., Pillard, F., Klapouszczak, A. Reynish, E., Thomas, D., Andrieu, S., ... Vellas, B. (2007). Exercise Program for Nursing Home Residents with Alzheimer's Disease: A 1-Year Randomized, Controlled Trial. Journal of American Geriatric Society, 55(2), 158-165. doi: 10.1111/j.15325415.2007.01035.x

Secrest, J., Iorio, D. H., \& Martz, W. (2005). The meaning of work for nursing assistants who stay in long-term care. Journal of Clinical Nursing, 14 (2), 90-97. doi: 10.1111/j.1365-2702.2005.01282.x

Shrout, P. E. \& Fleiss, J.L. (1979). Intraclass correlations: Uses in assessing rater reliability. Psychological Bulletin, 86(2), 420-428. 
Empowering staff in dementia long-term care

Sidani, S., LeClerc, C., \& Streiner, D. (2009). Implementation of the abilities-focused approach to morning care of people with dementia by nursing staff. International Journal of Older People Nursing, 4(1),48-56. doi: 10.1111/j.17483743.2008.00154.x

Sloane, P. D., Miller, L. L., Mitchell, C. M., Rader, J., Swafford, K. \& Hiatt, S. O. (2007). Provision of morning care to nursing home residents with dementia: Opportunity for improvement?. American Journal of Alzheimer's Disease and Other Dementias, 22, 369-377. doi: 10.1177/1533317507305593.

Sousa, L., Galante, H. \& Figueiredo, D. (2003). Qualidade de vida e bemestar dos idosos - um estudo exploratório na população portuguesa. Revista de Saúde Pública, 37(3), 364-371. doi: 10.1590/S003489102003000300016

Tappen, R.M., Roach, K.E., Applegate, E.B., Stowell, P. (2000) Effect of a combined walking and conversation intervention on functional mobility of nursing home residents with Alzheimer disease. Alzheimer Disease and Associated Disorders, 14(4), 196-201.

Testad, I., Mikkelsen, A., Ballard, C. \& Aarsland, D. (2010). Health and well-being in care staff and their relations to organizational and psychosocial factors, care staff and resident factors in nursing homes. International Journal of Geriatric Psychiatry, 25, 789-797. doi: 10.1002/gps.2419

Vernooij-Dassen, M. \& Olde Rikkert, M. (2004). Personal disease management in dementia care. International Journal of Geriatric Psychiatry, 19: 715-717.

Visser, S. M., Mccabe, M. P., Hudgson, C., Buchanan, G., Davison, T. E., \& George, K. (2008). Managing behavioural symptoms of dementia: Effectiveness of staff 
Empowering staff in dementia long-term care

education and peer support. Aging \& Mental Health, 12 (1), 47-55. doi: $10.1080 / 13607860701366012$

Weert, J. C. M. van, Dulmen, A. M. van, Spreeuwenberg, P. M. M., Ribbe, M. W., \& Bensing, J. M. (2005a). Effects of snoezelen, integrated in $24 \mathrm{~h}$ dementia care, on nurse-patient communication during morning care. Patient Education and Counseling, 58(3), 312-326. doi: 10.1016/j.pec.2004.07.013

Weert, J. C. M. van, Dulman, A. M., van, Spreeuwenberg, P. M. M., Ribbe, M. W., \& Bensing, J. M. (2005b). Behavioral and mood effects of snoezelen integrated into 24-hour dementia care. Journal of the American Geriatrics Society, 50(1), 24-33. doi: 10.1111/j.1532-5415.2005.53006.x

Weert, J. C. M. van, Dulmen, A. M. van, \& Bensing, J. M. (2008). What factors affect caregiver communication in psychogeriatric care? In A. M. Visser (Ed.) Alzheimer's Disease: New research. (pp. 87-117). New York: Nova Science Publishers.

Weert, J. C. M. van, Janssen, B. M., Dulmen, A. M. van, Spreeuwenberg, P. M. M., Bensing, J. M. \& Ribbe, M. W. (2006). Nursing assistants’ behavior during morning care: effects of the implementation of snoezelen, integrated in 24-hours dementia care. Journal of Advanced Nursing, 53(6), 656-668. doi: $10.1111 / \mathrm{j} .1365-2648.2006 .03772 . x$

Weert, J. C. M. van, Kerkstra, A., Dulmen, A. M. van, Bensing, J. M., Peter, J. G., \& Ribbe, M. W. (2004). The implementation of snoezelen in psychogeriatric care: an evaluation through the eyes of caregivers. International Journal of Nursing Studies, 41, 397-409. doi: 10.1016/j.ijnurstu.2003.10.011

Wells, D.L., Dawson, P. (2000). Description of retained abilities in older persons with dementia. Research in Nursing \& Health,23(2),158-166. 
Empowering staff in dementia long-term care

Wood, W., Womack, J., \& Hooper, B. (2009). Dying of Boredom: An Exploratory Case Study of Time Use, Apparent Affect, and Routine Activity Situations on Two Alzheimer's Special Care Units. American Journal Occupational Therapy, 63(3), $337-350$.

Zimmerman, S., Williams, C., Reed, P., Boustani, M., Preisser, J., Heck, E. \& Sloane, P. (2005). Attitudes, stress, and satisfaction of staff who care for residents with dementia. The Gerontologist, 45(1), 96-105. doi: 10.1093/geront/45.suppl_1.96. 
Empowering staff in dementia long-term care

Table 1. Characterization of participants: staff and residents $(n=6)$

\begin{tabular}{|c|c|c|}
\hline \multicolumn{3}{|l|}{ Staff $(n=6)$} \\
\hline \multicolumn{3}{|l|}{ Gender } \\
\hline Female $(\mathrm{n}, \%)$ & 6 & 100 \\
\hline \multicolumn{3}{|l|}{ Age } \\
\hline Mean, SD (years) & 40.0 & 11.91 \\
\hline Minimum, maximum (years) & 23 & 51 \\
\hline \multicolumn{3}{|l|}{ Academic qualifications } \\
\hline 1 st cycle $(\mathrm{n}, \%)$ & 1 & 16.67 \\
\hline 2nd cycle $(\mathrm{n}, \%)$ & 1 & 16.67 \\
\hline 3rd cycle (n, \%) & 1 & 16.67 \\
\hline Secondary school (n, \%) & 1 & 16.67 \\
\hline Higher School (n, \%) & 2 & 33.33 \\
\hline \multicolumn{3}{|l|}{ Working years in the institution } \\
\hline Mean, SD (years) & 5.00 & 5.99 \\
\hline \multicolumn{3}{|l|}{ Residents $(n=6)$} \\
\hline \multicolumn{3}{|l|}{ Gender } \\
\hline Female (n, \%) & 4 & 66.7 \\
\hline Male (n, \%) & 2 & 33.3 \\
\hline \multicolumn{3}{|l|}{ Age } \\
\hline Mean, SD (years) & 80.83 & 10.87 \\
\hline Minimum, maximum (years) & 66 & 93 \\
\hline \multicolumn{3}{|l|}{ Clinical diagnosis } \\
\hline Moderate dementia (n, \%) & 4 & 66.7 \\
\hline Severe dementia $(\mathrm{n}, \%)$ & 2 & 33.3 \\
\hline \multicolumn{3}{|c|}{ Cognitive Decline Test of the EASYcare } \\
\hline Mean, SD (points) & 20.67 & 6.25 \\
\hline \multicolumn{3}{|l|}{ Barthel Index } \\
\hline Total dependency $(\mathrm{n}, \%)$ & 3 & 50.0 \\
\hline Moderate dependency $(\mathrm{n}, \%)$ & 2 & 33.3 \\
\hline Slight dependency $(\mathrm{n}, \%)$ & 1 & 16.7 \\
\hline
\end{tabular}


Table 2: Psycho-educational sessions for staff

Session

1. Presentations of the participants and the multidisciplinary team

What is Dementia?

Basic information about dementia

Multi-sensory stimulation strategies: Olfaction

The senses as a way to communicate effectively with residents in advanced stages of dementia; adjust the stimuli to residents' needs and preferences; practical strategies to stimulate residents' olfaction during the day.

Emotional impact of caregiving

Group discussion about the positive and negative impacts of the caregiving experience on personal, professional and familiar life.

Relaxation: Abdominal breathing

Assignment: Identify personal sources of stress and respective management strategies

2. Communication in Dementia

Verbal and non-verbal strategies to communicate effectively with patients with dementia; find appropriate solutions for a challenging episode in which a staff member experienced difficulties in communicating with a resident with dementia

Multi-sensory stimulation strategies: (Con)tact

Stimulate the tact: physical contact with people and objects; practical strategies to stimulate residents' tact during the day

Deal with emotions

Improve emotion-management strategies; find a situation associated with negative emotions and play the game "six colors to think" (based on Bono, 1985) to test how different thoughts may induce different emotions.

Relaxation: Stretching

Assignment: Fill post-its with positive words or phrases

3. Multi-sensory stimulation strategies: Vision

Potential aged-related and dementia-related visual changes and its impact on the resident with dementia (e.g. disorientation, confusion, physical dependency); types of stimulation: facial expressions, gestures, colors and light contrasts, orientation aids; practical strategies to stimulate the sense of vision during the day.

Assertiveness

How to communicate in an assertive way using the DESC (Describe; Explain; Specify;

Conclude) technique (Bower \& Bower, 2004); role-play using the DESC technique.

Relaxation: Cognitive relaxation technique

Assignment: Use the assertive training in at least one situation.

4. Multi-sensory stimulation strategies: Audition

Balance auditory stimulation: "good" stimulation (e.g., music, nature sounds, verbal communication) vs. "bad" stimulation (e.g., machines working or doors slamming); how to use the different types of communication during residents' daily care

Social support

The importance of social networks; discussion group about ways to enhance or maintain social support (e.g., develop contacts)

Relaxation: Progressive muscle technique

Assignment: Contact a person (colleague, friend, neighbour or family member) 
5. Multi-sensory stimulation strategies: Taste

The sense of the taste as one of the most pleasurable senses for residents with dementia; practical strategies to stimulate the taste during and between meals

\section{Self-care}

The importance of self-care; think about the time participants devoted to themselves, to work, and to family; group discussion of main findings

Relaxation: Autogenic technique

Assignment: Think in one leisure activity and plan the date for accomplish it

6. Elderly engagement: (im)Possible mission?

The functional potential of the residents with dementia: "what they can do" vs "what they do"; strategies to stimulate residents' participation: levels of assistance provided by caregiver, verbal and non-verbal communication, physical guidance; break the small steps of an activity; choose an example of a resident to identify what steps he/she can(not) do (e.g. independent, need assistance, dependent)

Problem-solving

Find a challenging episode shared by all participants and find solutions to overcome it, using the problem-solving technique (i) identify the problem; ii) explain the problem; ii) create solutions; iv) choose one solution; v) plan the implementation of the solution; vi) evaluate the efficacy)

Relaxation: Mitchell method

Assignment: Practise one of the learnt relaxation techniques

7. Challenging behaviours: How to cope?

Types of behaviour (passive behaviours, mood changes - agitation, anxiety-, disorientation, repetitive questions, etc.) and possible factors to its occurrence (organic factors associated with the condition, factors related to residents' life history, environmental factors); strategies to deal with challenging situations; describe a challenging situation with a resident with dementia; identify the type of behaviour; find possible solutions to deal with the situation and to avoid it

Cope with grief

Think on the emotions which are associated with the death of residents and strategies to cope with it.

Relaxation: Progressive muscle training

Assignment: Bring an object that symbolised their participation in the program.

8. For a safer environment: What can we do?

Risk factors for falls: age-related and dementia-related intrinsic factors; extrinsic factors; providing a secure environment for the stimulation of residents' participation in daily activities; identifying extrinsic factors and finding solutions to eliminate or limit them

Celebration and finalization 
Empowering staff in dementia long-term care

Figure 1 - Residents behaviour during morning care routines, before and after the intervention

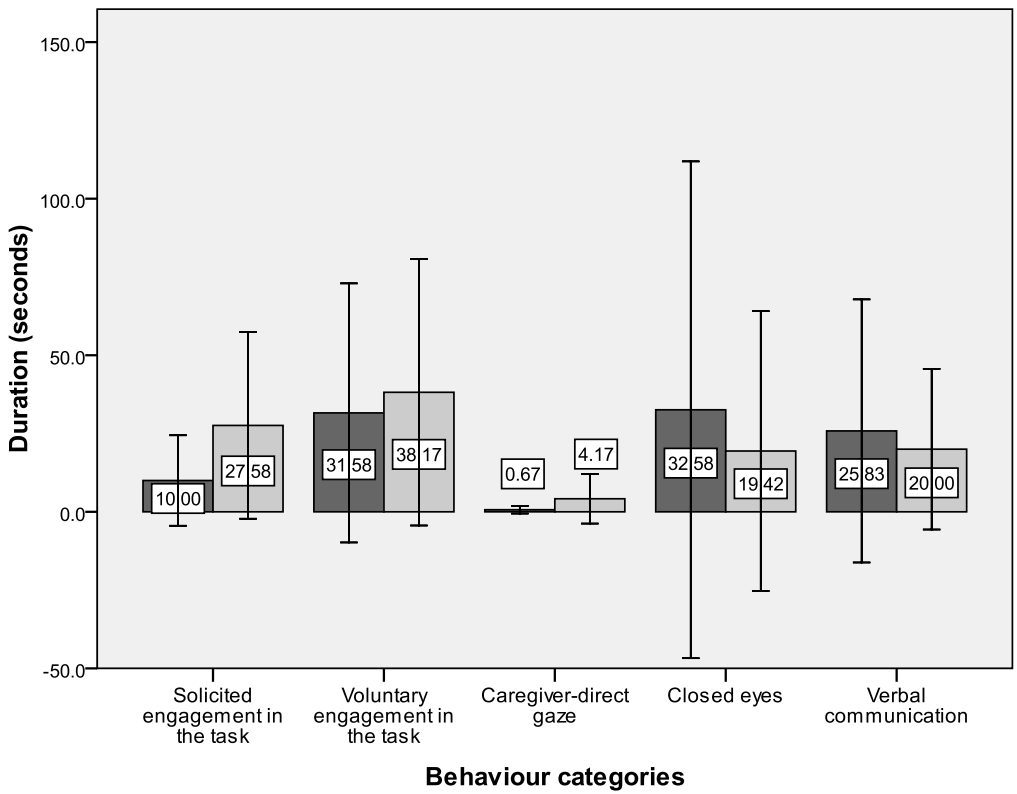

$\square$ Pre-intervention

$\square$ Post-intervention

Behaviour categories 
Empowering staff in dementia long-term care 